\title{
Regeneration Approaches for Dental Pulp and Periapical Tissues with Growth Factors, Biomaterials, and Laser Irradiation
}

\section{Chiaki Kitamura $^{1{ }^{*},}$, Tatsuji Nishihara ${ }^{2}$, Masamichi Terashita ${ }^{3}$, Yasuhiko Tabata $^{4}$, Eijiro Jimi ${ }^{5}$, Ayako Washio ${ }^{1}$ and Shizu Hirata ${ }^{1}$}

1 Division of Pulp Biology, Operative Dentistry, and Endodontics, Department of Cariology and Periodontology, Kyushu Dental College, Manazuru 2-6-1, Kokurakita, Kitakyushu 803-8580, Japan; E-Mails: ayacchi@kyu-dent.ac.jp (A.W.); r07hirata@fa.kyu-dent.ac.jp (S.H.)

2 Division of Infections and Molecular Biology, Department of Health Promotion, Kyushu Dental College, Manazuru 2-6-1, Kokurakita, Kitakyushu 803-8580, Japan; E-Mail: tatsujin@kyu-dent.ac.jp (T.N.)

3 Division of Comprehensive Dentistry, Department of Clinical Communication and Practice, Kyushu Dental College, Manazuru 2-6-1, Kokurakita, Kitakyushu 803-8580, Japan; E-Mail: tera-m@kyu-dent.ac.jp (M.T.)

4 Department of Biomaterials, Institute for Frontier Medical Sciences, Kyoto University, 53 Kawara-cho, Shogoin, Sakyo-ku, Kyoto 606-8507, Japan;

E-Mail: yasuhiko@frontier.kyoto-u.ac.jp (Y.T.)

5 Division of Molecular Signaling and Biochemistry, Department of Biosciences, Kyushu Dental College, Manazuru 2-6-1, Kokurakita, Kitakyushu 803-8580, Japan; E-Mail: ejimi@kyu-dent.ac.jp (E.J.)

* Author to whom correspondence should be addressed; E-Mail: chi-aki-k@kyu-dent.ac.jp; Tel.: +81-93-582-1131; Fax: +81-93-581-5399.

Received: 4 August 2011; in revised form: 26 September 2011 / Accepted: 11 October 2011 / Published: 12 October 2011

\begin{abstract}
In current dental practice, restorative and endodontic procedures have been developed in an attempt to preserve the vitality of dental pulp after exposure to external stimuli such as caries infection. When damage to dental pulp is reversible, pulp wound healing can proceed, whereas irreversible damage induces pathological changes in dental pulp, eventually requiring its removal. Furthermore, dentists sometimes extract non-vital teeth because of severe caries progression, critical size of periapical lesion, and tooth fracture. To overcome the limitations of presently available therapies, it is important to
\end{abstract}


develop regeneration therapy for dental pulp and periapical tissues. In this review, we focus on the regeneration of dental pulp and periapical tissues by application of exogenous growth factors and scaffolds, as well as low-intensity laser irradiation as an auxiliary therapy for regeneration therapy.

Keywords: dental pulp regeneration; regeneration of bone defects; FGF2; gelatin hydrogels; laser irradiation

\section{Introduction}

One of the universal facts for dentists is that preservation and maintenance of dental pulp viability are essential to avoid tooth loss. Dental pulp is sometimes affected by external stimuli such as caries infection or traumatic injury. In current dental practice, when dentists find a deep dental caries with vital and reversible dental pulp, they remove infected enamel and dentin, and carry out restorative procedures with pulp capping or pulpotomy. Pulp capping and pulpotomy with biomaterials such as calcium hydroxide are accepted as effective procedures to induce pulp wound healing, including some processes such as apoptosis of odontoblasts and dental pulp cells in the initial phase, followed by reactionary and reparative dentinogenesis in the late phase [1-5]. Reactionary dentin is formed by surviving odontoblasts, and reparative dentin is formed by odontoblast-like cells differentiated from dental pulp stem cells or residual dental pulp [6-8].

When dentists find a severe defect with a critical size of the resultant exposure of dental pulp, there are no effective treatments to preserve the viability of dental pulp from the irreversible damage, and dentists carry out endodontic procedures including complete removal of dental pulp (pulpectomy), irrigation of the root canal mechanically and chemically to regulate inflammatory responses of apical area of the periodontal ligament, and fill the root canal with biomaterials such as a gutta-percha to prevent re-infection by bacteria (Figure 1).

Figure 1. (a) Before pulpectomy of left maxillary canine; (b) Dental pulp exposure after removal of infected dentin; (c) Root canal after preparation and irrigation; (d) Root canal filling.
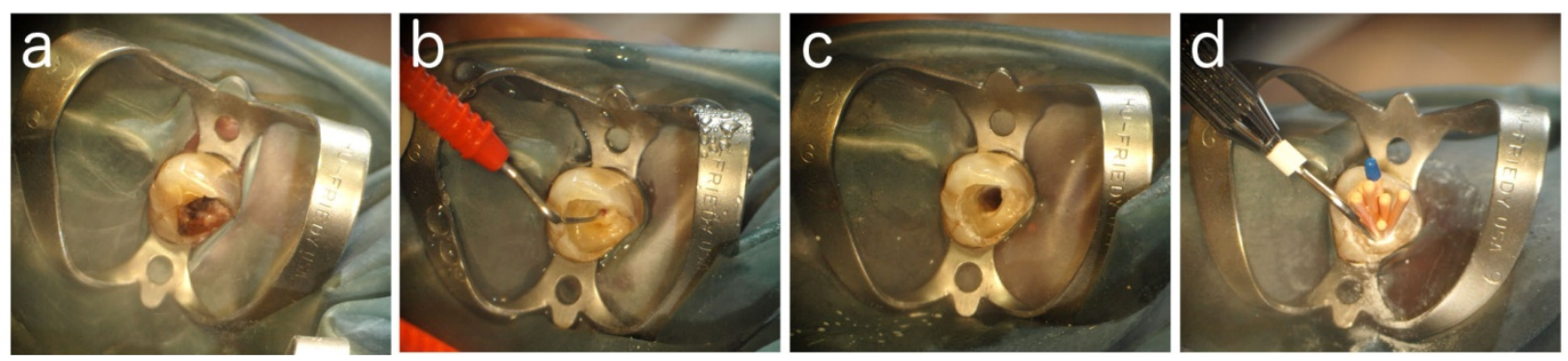

Furthermore, persistent periapical lesion at a treated tooth sometimes occurs because of its complicated anatomical structure or inadequate treatment by dentists. Dentists carry out endodontic surgery such as apicectomy to induce wound healing and regeneration of periapical tissues (Figure 2). 
Figure 2. (a) Fistula formed at buccal site of left maxillary first premolar; (b) Incision for apicectomy; (c) After removal of root apex and infected granulation tissue; (d) Radiophotograph of (a). Periapical lesion (arrow) was observed; (e) After apicectomy. Bone defect (arrow) was observed; (f) Three months after surgery. Bone formation (arrow) was observed.

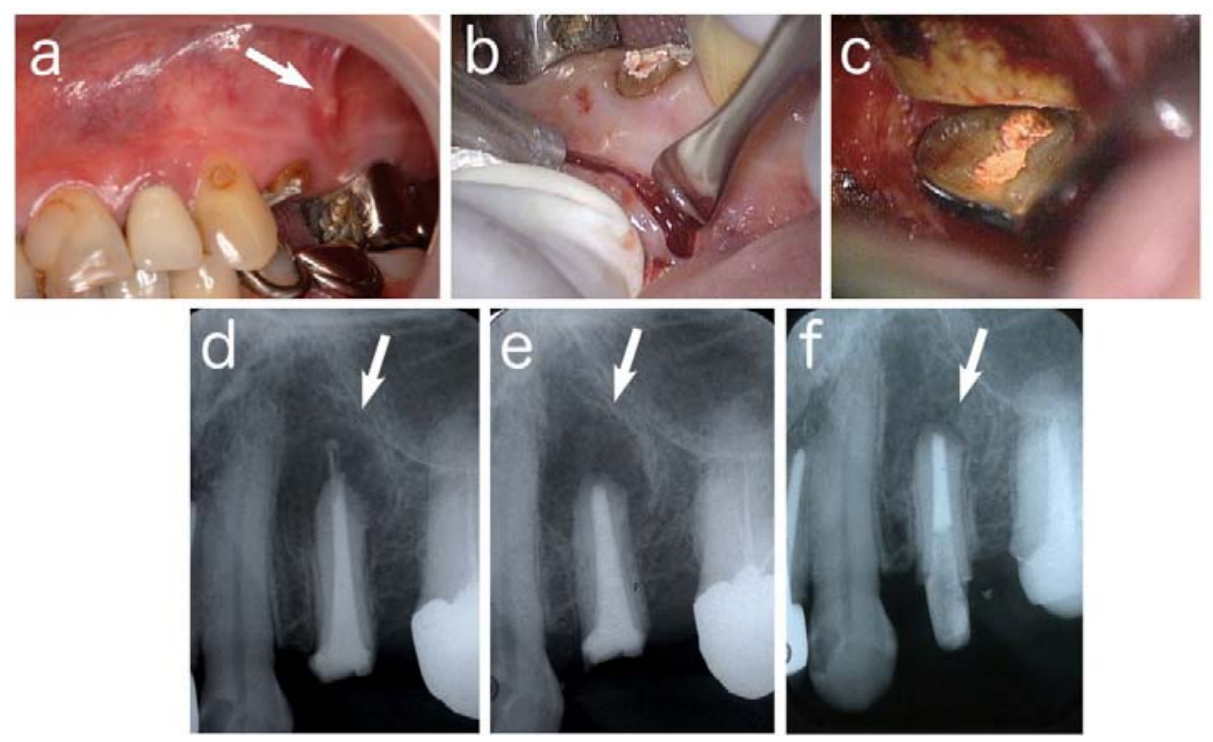

However, a tooth without vital dental pulp has lost its defensive ability, which is often followed by severe damage such as progression of deep radicular caries or tooth facture, resulting in the extraction of the tooth to preserve further expansion of the uncontrollable infection (Figure 3). It is reported that the success rate of endodontic retreatment is lower than that of initial treatment [9-12].

To overcome these limitations in the available therapy to preserve a functional tooth in the present dentistry, it is important to develop regeneration therapy for dental pulp and periapical tissues.

Figure 3. (a) Root fracture of right mandibular second molar; (b) Critical size of periapical lesion of maxillary incisors.

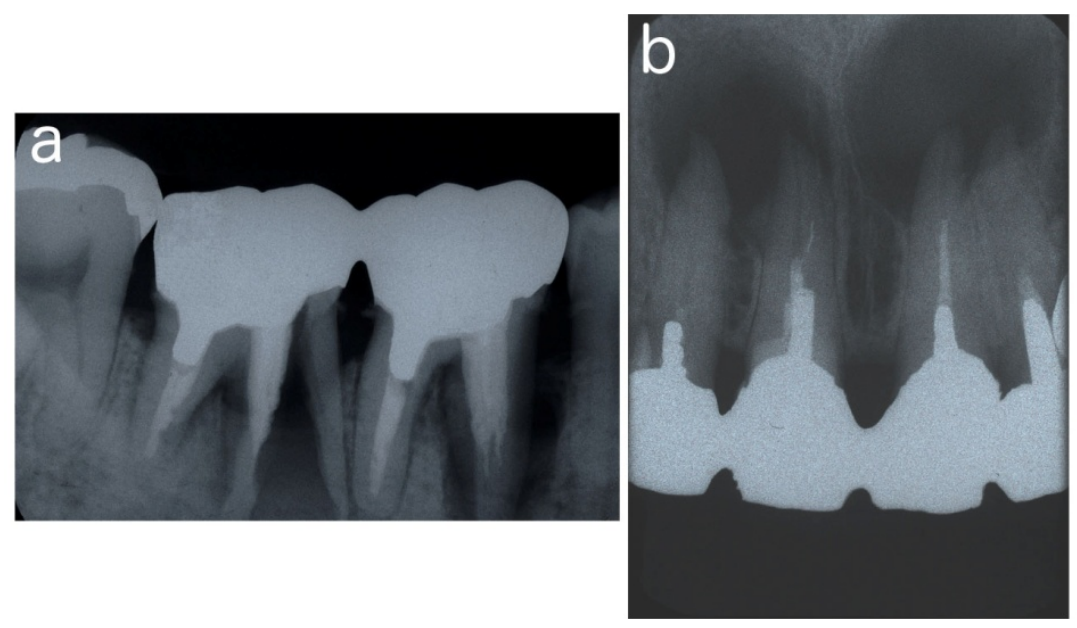




\section{Strategies for Local Regeneration of Dental Pulp and Periapical Tissues}

It is well known that essential three factors to achieve tissue engineering are stem cells, growth factors, and scaffolds [13]. Stem cells, which are supplied from tissues around or outside of the target area, differentiate into specific cells to regenerate tissue defects. Growth factors such as bone morphogenetic proteins (BMPs) and fibroblast growth factors (FGFs), which are mainly supplied from outside of the target, induce proliferation and differentiation of stem cells. Scaffolds with properties of extracellular matrix temporally support structures for cell growth, differentiation, and tissue formation. In research for tissue regeneration of dental pulp and periapical tissues, these three factors are appropriately combined and applied to the target area.

Figure 4. Schemes of strategies for the regeneration therapy of dental pulp and periapical tissues. (a) Regeneration of the entire tooth. In the strategy, a tooth germ is regenerated by growth factors, scaffolds, and stem cells in organ culture; (b) Regeneration of dental pulp and dentin. This strategy is further classified into two ways. One is the regeneration by the combination of supplied tissue engineering factors including growth factors, scaffolds, and stem cells. The other is the regeneration by supplied growth factors and scaffolds, and stem or progenitor cells are induced from residual tissues; (c) Regeneration of periapical tissues by the combination of tissue engineering factors with external stimulation such as laser irradiation.

(a). Regeneration of Entire Tooth

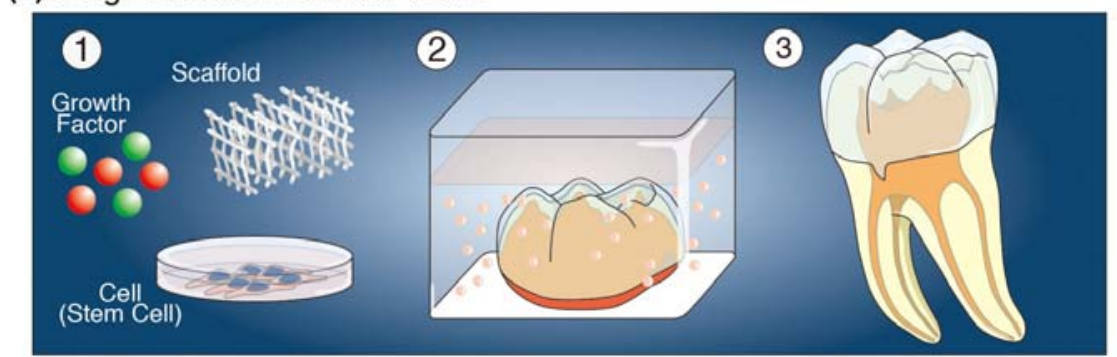

(b). Regeneration of Dental Pulp

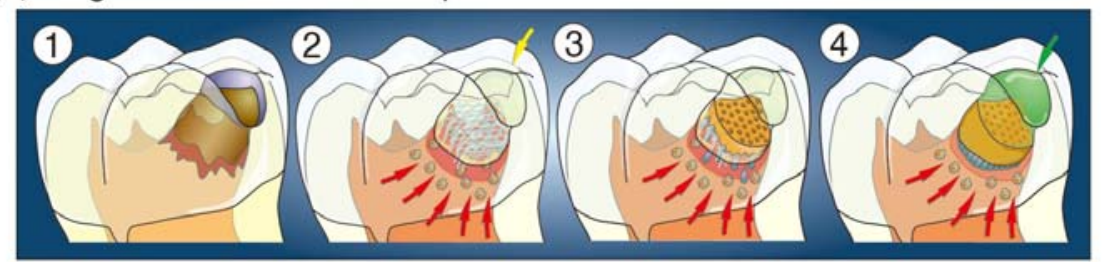

(c). Regeneration of Periapical Tissues

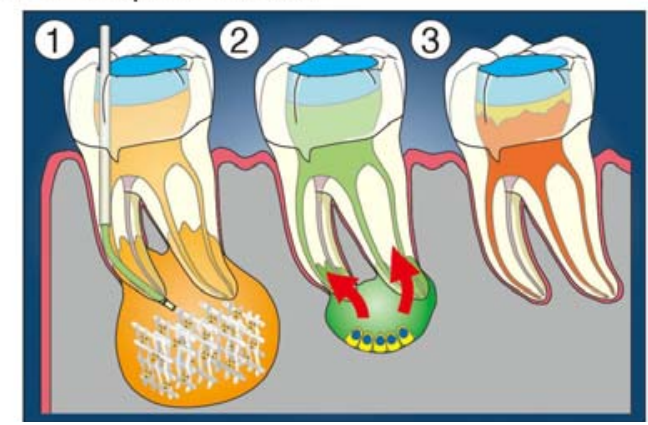

Strategies to develop the regeneration therapy of dental pulp and periapical tissues are usually classified into two types. One is the regeneration of the entire tooth, and the other is the local 
regeneration of dental pulp and periapical tissues from residual tissues around defect area. Furthermore, the local regeneration is classified into three types as follows (Figure 4); (1) Regeneration in which three factors are supplied from outside; (2) Regeneration in which growth factors and scaffolds are supplied from outside, while stem or progenitor cells are induced from the residual tissues; and (3) Regeneration by outside stimulation such as laser irradiation.

\subsection{Strategy 1: Regeneration of Entire Tooth}

Organ replacement therapy to a defective body part is one of important research area in medicine. Organ Technologies plans to develop many basic technologies that will create three-dimensional organs for the future organ replacement regenerative medicine. There are many research challenges such as how cells should be manipulated for three-dimensional reconstruction, what types of cells should be used, and how the organ size should be controlled.

Regeneration of the entire tooth is accepted as a model of organ replacement and regeneration therapy. Recently, it was reported that tooth germs can be bioengineered using a three-dimensional organ-germ culture method, in which dental epithelial and mesenchymal cells isolated from tooth germs were cultured in three-dimensional scaffolds for the replacement therapy. Scaffolds used in the research are synthetic polymers such as poly(lactide-co-glycolide) (PLGA) and bioceramics such as hydroxyapatite, tricalcium phosphate and calcium carbonate hydroxyapatite [14-21]. It was also reported that bioengineered teeth were generated from three-dimensionally arranged dental epithelial and mesenchymal cells in collagen gels by in vitro cell aggregate and manipulation methods, and that the bioengineered tooth germs generated a structurally correct tooth showing penetration of blood vessels and nerve fibers were transplanted into mouse maxilla, resulting in a successful fully functioning tooth replacement [22-25]. These bioengineered teeth, however, were reconstructed from dental epithelial and mesenchymal cells. Further research will be needed to regenerate the entire tooth from other cell sources such as induced pluripotent stem cells.

\subsection{Strategy 2: Local Regeneration of Dental Pulp from Residual Tissue}

Regeneration of dental pulp from residual dental pulp has mainly been challenged by researchers who are engaged in clinical practice. Several lines of studies have reported the use of applications of bioactive molecules such as BMPs and recombinant fusion ameloblastin to exposed dental pulp [26-28]. However, the application of bioactive molecules without scaffolds onto the exposure site of dental pulp only induces reparative dentin formation toward residual dental pulp underneath the defect area. The results of the challenge are the same as those provided by conventional therapy such as pulp capping.

Induction of dental pulp proliferation and newly regenerated dentin in a defect is essential for local regeneration of a tooth. Many researchers are trying to induce the formation of new dentin by odontoblast-like cells that are differentiated from newly proliferating dental pulp. Several papers have demonstrated the local regeneration of dental pulp and dentin by different methods. It was reported that the combination of BMP4 with dentin powder induced dentinogenesis in a cavity with pulp exposure [29], and that ultrasound-mediated gene delivery of growth factors such as growth/differentiation factor 11 (GDF11)/BMP11 into dental pulp stem cells by in vivo sonoporation 
induced reparative dentinogenesis [30-32]. In this research, stem or progenitor cells were induced from residual pulp through the exposure site at the bottom of the cavity. It was also indicated that the ex vivo gene therapy by the transplantation of pulp stem/progenitor cells transfected with some growth factors such as GDF11/BMP11 stimulated reparative dentinogenesis [33-36].

Recently, FGF2 has been applied with gelatin hydrogels and collagen sponge to develop the regeneration therapy of dental pulp. FGF2 is known to play a role in both physiological and pathological conditions [37-39]. Gelatin hydrogels were used as a carrier of FGF2. It was previously demonstrated that biologically active FGF2 was gradually released into target are of a tissue defect by in vivo biodegradation of gelatin hydrogels that incorporated FGF2 [40-43] (Figure 5).

Figure 5. Scheme for controlled release of growth factors from gelatin hydrogels. (a,b) Preparation of gelatin hydrogels incorporating growth factors. Growth factors are impregnated into gelatin hydrogels through immersion of gelatin hydrogels into solution of growth factors; (c) Implantation of gelatin hydrogels incorporating growth factors with scaffolds such as collagen sponge into a tissue defect area; (d,e) In the defect area, growth factors are gradually released from gelatin hydrogels through the biodegradation of gelatin hydrogels by collagenase or gelatinase. This controlled release of growth factors induces stem or progenitor cells into the scaffold, resulting in the regeneration of tissue into target area.

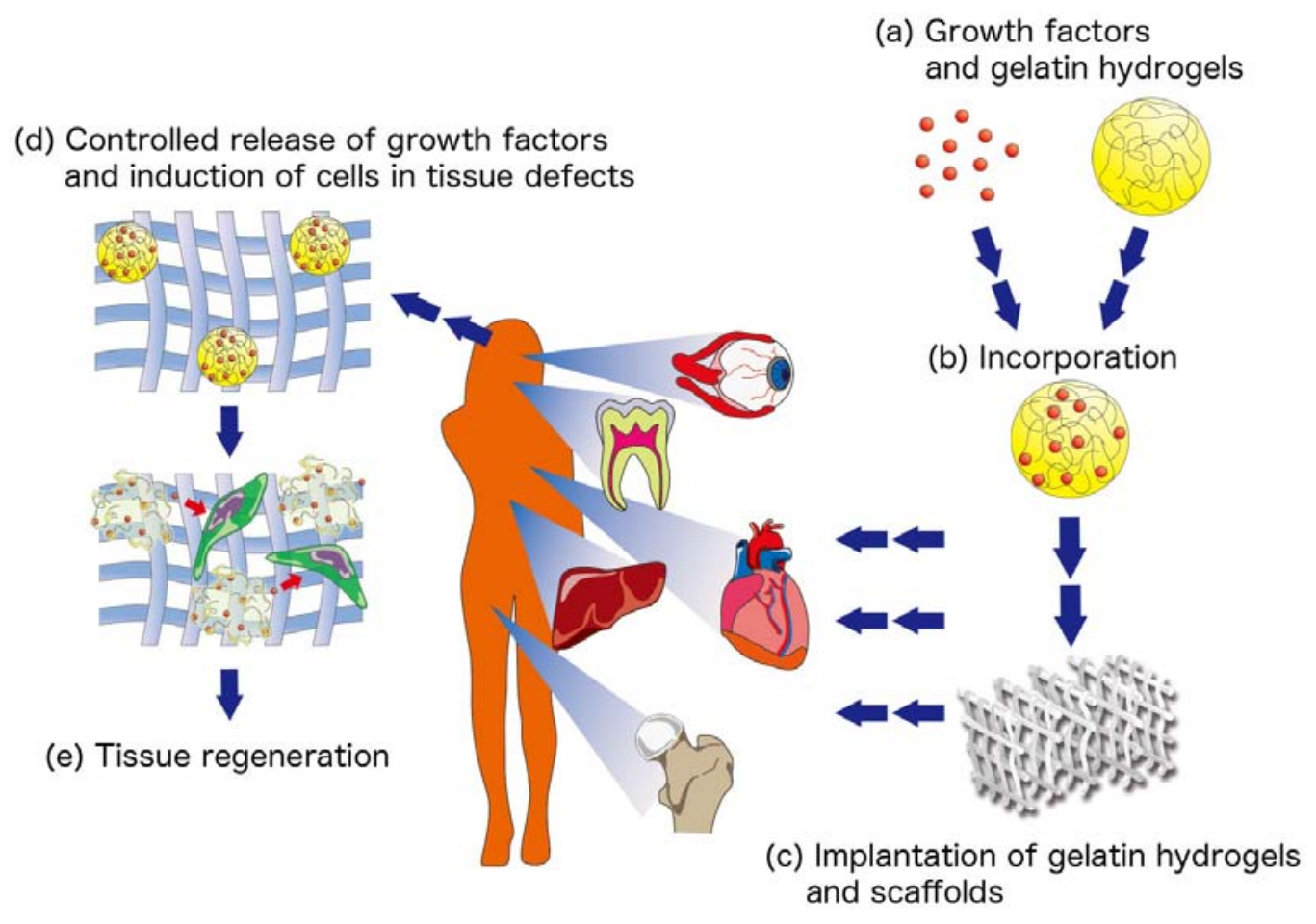

We implanted free FGF2 or gelatin hydrogels incorporating FGF2 with collagen sponge into dentin defects above amputated pulp, and found that a non-controlled release of free FGF2 only accelerated reparative dentin formation in the residual dental pulp, whereas a controlled release of an appropriate dosage of FGF2 from gelatin hydrogels induced the formation of the dentinal bridge-like osteodentin on the surface of the regenerated dental pulp in the defect (Figure 6). These results suggest that our method is different from the conventional therapy that induces reparative dentinogenesis toward the residual pulp $[44,45]$, and show the possibility of local regeneration of dental pulp. 
Figure 6. (a) Experimental procedures; (b) Regeneration of dental pulp and dentin by controlled release of FGF2 from gelatin hydrogels. Regenerative Dentin (arrow) on the surface of regenerated pulp was observed. Arrowhead and dotted line; amputated line of dental pulp; (c) Difference between wound healing and reparative dentin formation by pulp capping and regeneration of dental pulp and dentin by controlled release of FGF2.

(a) Experimental Procedures

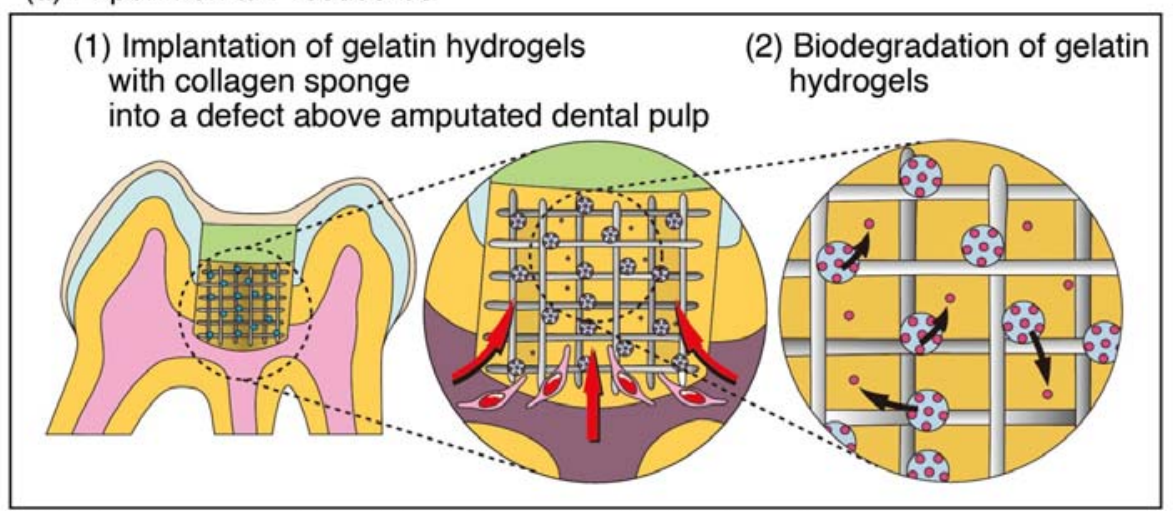

(b) Regenration of Dental Pulp 3 weeks after Implantation Implantation of gelatin hydrogels Implantation of gelatin hydrogels without FGF2 incorporating FGF2
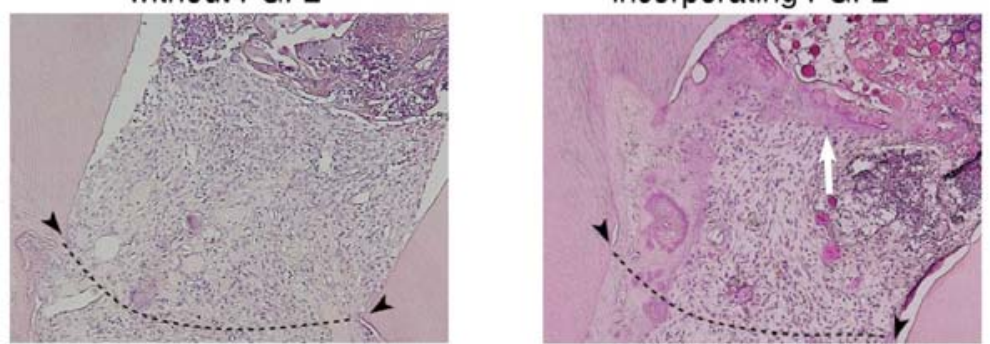

(c) Difference between Wound Healing and Regeneration of Dental Pulp

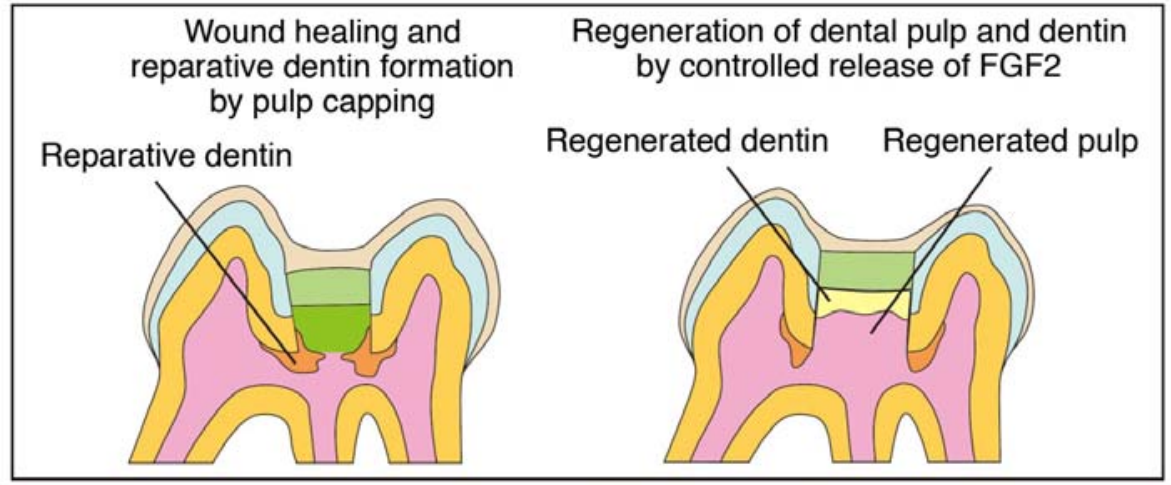

Periapical tissues are also the source for stem or progenitor cells when root formation is not completed. It was demonstrated that stem cells exist in the apical areas of developing teeth in which root formation is not complete. Moreover, in studies on the local regeneration of dental pulp from periapical tissues, the induction of tissue regeneration from these stem cells has been attempted. It is suggested that the existence of a new population of mesenchymal stem cells residing in the apical papilla (SCAPs) of incompletely developed teeth, and these cells have the ability to differentiate into odontoblast-like cells [46-48]. SCAPs play important roles in continued root formation, and have been suggested to participate in pulp wound healing and regeneration. It is also known that bone marrow-derived mesenchymal stem cells (BMMSCs) have multipotent abilities to differentiate into 
several cell types and undergo osteogenic differentiation. Periapical tissues include periodontal ligament, and bone marrow, which is the source of BMMSCs [49-54]. Localization of SCAPs and BMMSCs in the apical area indicate the possibility of the induction of these stem cells for local regeneration of dental pulp.

\subsection{Strategy 3: Regeneration by Laser Irradiation}

Effects of laser irradiation on tissue and organs are widely investigated. In dentistry, a variety of lasers such as helium-neon laser, erbium-doped: yttrium, aluminum, and garnet laser, galliumaluminum-arsenium (Ga-Al-As) laser, and carbon dioxide laser, are used in clinic and research. Many researchers in dentistry are interested in clarifying effects of low intensity laser therapy (LILT) on wound healing or regeneration of defects occurring in tissues such as bone, dental pulp, and mucosa. It has been shown that LILT offers numerous benefits in clinical practice, including pain relief [55], regeneration of severed nerves [56,57], anti-inflammation [58,59], and wound healing [60,61]. Tissue change occurred in the defect area by LILT is called 'wound healing,' 'tissue repair', or 'regeneration'. Terms 'wound healing' or 'tissue repair' are used when LILT is singly applied, while a term 'regeneration' is used when LILT is applied with tissue engineering factors such as growth factors or scaffolds.

Several lines of studies reported effects of LILT on wound healing of dental pulp [62-65]. They analyzed histological change of exposed dental pulp, and indicated that LILT accelerated wound healing of dental pulp and the induction of reparative dentin. Reparative dentin is formed in residual dental pulp, not in the dentin defect area. At the time of writing, no report has yet been made about dental pulp regeneration by LILT.

The application of LILT on bone regeneration has been well studied. Effects of LILT on bone wound healing remain inconclusive [66-70]. In contrast, several lines of studies reported that the combination of LILT with growth factors or biomaterials accelerates osteoblast differentiation and bone regeneration. It has been indicated that the combination of LILT with graft of autologous bone or inorganic bovine bone [71-74], enamel matrix derivative [75], and BMPs [76-78] accelerated bone regeneration, compared with LILT alone or biomaterials alone. Recently, we examined effects of LILT by Ga-Al-As laser on BMP2 induced osteoblastogenesis [79], and found that low intensity laser irradiation accelerated BMP2-induced transcription factors such as Id1, Osterix, and Runx2, expressions of type I collagen, osteonectin, and osteocalcin mRNA, markers of osteoblasts, and activation of Smad1/5/8 as well as alkaline phosphatase, in C2C12 myoblast cells that differentiate into osteoblasts by exposure to BMP2. Furthermore, this enhancement of BMP2-induced ALP activity and Smad phosphorylation by laser irradiation was also observed in primary osteoblasts, suggesting that low intensity laser irradiation accelerates the BMP2-induced differentiation of osteoblasts by stimulating the BMP/Smad signaling pathway (Figure 7). Taken together, LILT may be useful as an auxiliary therapy for regeneration of dental pulp and periapical tissues. 
Figure 7. Effects of low intensity laser therapy (LILT) on BMP2-induced osteoblastogenesis. Low intensity irradiation of garnet laser, gallium-aluminum-arsenium (Ga-Al-As) laser accelerated osteoblastogenesis of BMP2-exposed C2C12 cells and primary osteoblasts.

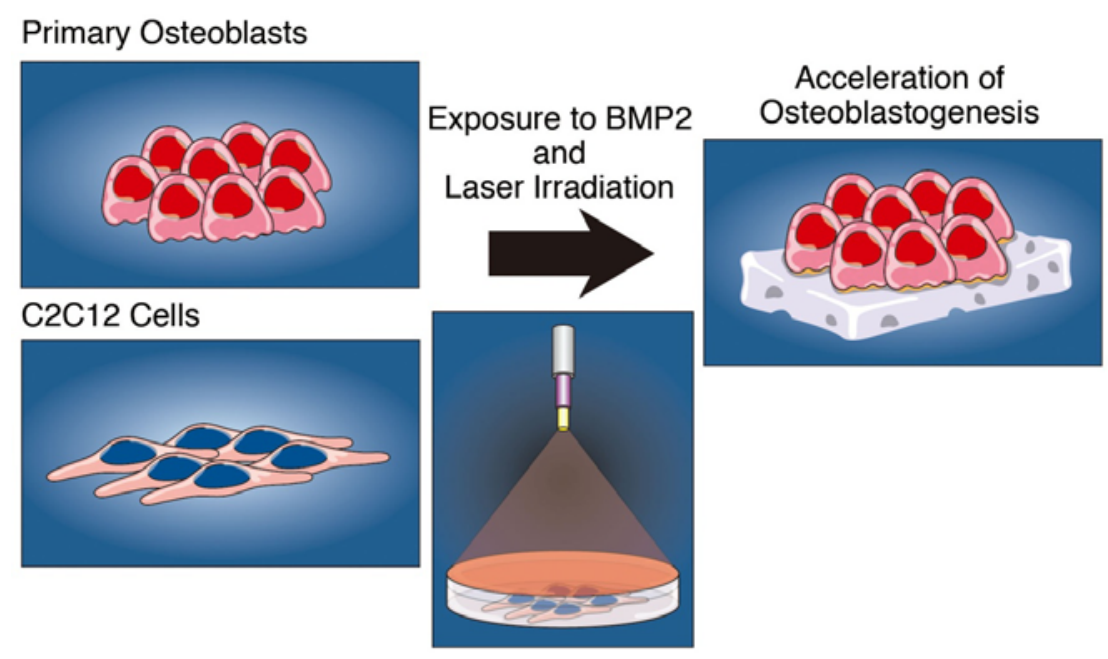

\section{Hyaluronic Acid Sponge, a Biomaterial as a Scaffold for Regeneration of Dental Pulp}

\subsection{Biomaterials as Scaffolds for Regeneration of Dental Pulp and Bone}

For successful tissue regeneration, the selection of appropriate scaffolds is an important step. It is well known that essential properties of scaffolds are mechanical properties such as porous three-dimension structure and mechanical strength, as well as biological properties such as biocompatibility and biodegradation [80]. The following biomaterials are utilized for present research of tissue regeneration therapy; polyethylene terephthalate, poly(L-lactide-co-D, L lactide), polylactic acid, polyglycolic acid, PLGA, polyvinyl alcohol, collagen, hyaluronic acid, hydroxyapatite, tricalcium phosphate, silk fibroin, bioactive glasses, and ceramic materials [81]. One of the naturally derived scaffolds, collagen sponge, has been found to be well suited to the regeneration of bone defects [82-84].

In our research about local regeneration of dental pulp by controlled release of FGF2, we used collagen sponge as a scaffold. However, in vivo and in vitro comparisons of suitable three-dimensional scaffold for the regeneration of dental pulp have only been investigated in the subcutaneous implantation of dental pulp stem cell line-seeding sponges in nude mice, not in dental pulp.

\subsection{Hyaluronic Acid Sponge for Dental Pulp}

Hyaluronic acid (HA) is one of glycosaminoglycans in extracellular matrix and plays important roles in maintaining morphologic organization by preserving extracellular spaces, and has been reported to have excellent potential for tissue engineering [85-89]. It was reported that HA shows important roles in some biological processes, including inhibition of inflammation and pain, and differentiation of osteoblastic and osteoclastic cells [90-92]. In addition, some researchers have reported that intra-articular HA treatment for patients with osteoarthritic knees reduced painful symptoms and improved joint mobility [93,94]. Dental pulp is a type of connective tissue, and contains 
large amounts of glycosaminoglycans [95,96]. Previously, the contribution of HA to the initial development of dentin matrix and dental pulp [97], in vivo application of HA gels on the wound healing processes of dental pulp, and the application of gelatin-chondroitin-hyaluronan tri-copolymer scaffold to dental bud cells were reported $[98,99]$.

Recently, we examined the in vitro and in vivo compatibility of HA sponge for regeneration of dental pulp by comparison of HA sponge with collagen sponge. We used KN-3 cells, which were established from rat dental pulp, have odontoblastic properties such as high alkaline phosphatase activity and calcification ability [100]. In vitro results showed that KN-3 cells adhered to HA sponge, as seen in collagen sponge. In vivo results, following implantation of both sponges in dentin defect areas, showed that dental pulp proliferation and invasion of vessels into both sponges were well induced from amputated dental pulp, suggesting that HA sponge has an ability to sustain dental pulp tissue regenerated from residual amputated dental pulp. Furthermore, we found that the inflammatory responses of KN-3 cells and the amputated dental pulp to HA sponge were lower than those against collagen sponge, suggesting that HA sponge has biocompatibility and biodegradation characteristics as well as an appropriate structure to make it suitable for dental pulp regeneration [101] (Figure 8).

Figure 8. (a) Effects of hyaluronic acid sponge on KN-3 cells and amputated dental pulp; (b) Effects of collagen sponge on KN-3 cells and amputated dental pulp. Arrowheads and dotted line; amputated line of dental pulp.

(a) Hyaluronic Acid Sponge
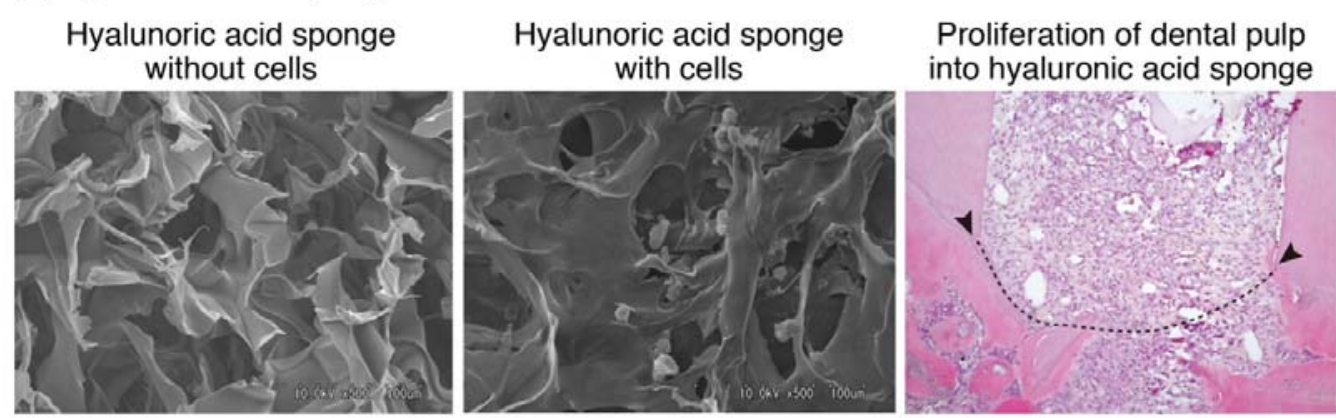

(b) Collagen Sponge
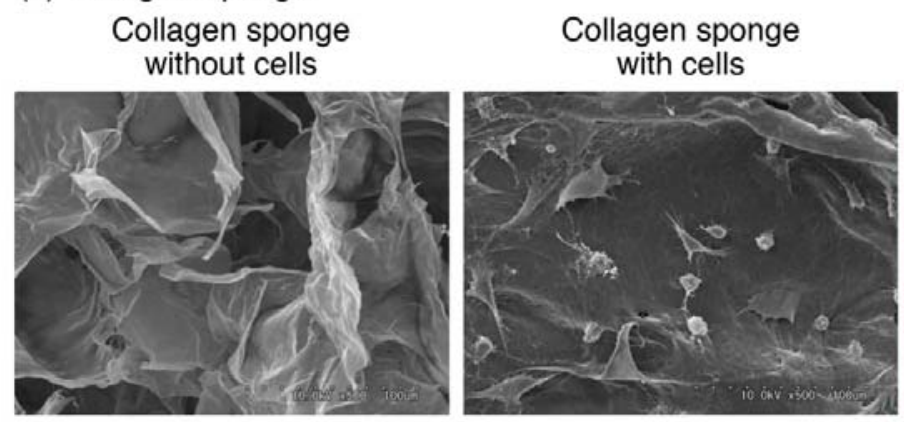

Proliferation of dental pulp into collagen sponge

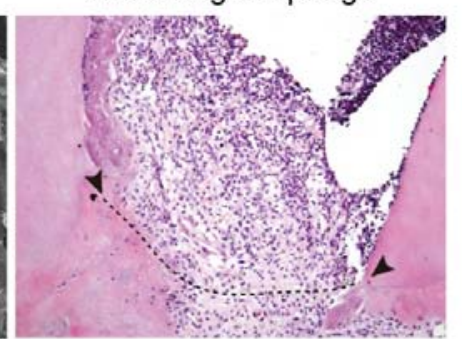

We also examined the effects of HA gel on neuronal differentiation of PC12 pheochromocytoma cells, which respond to nerve growth factor (NGF) by extending neurites and exhibit a variety of properties of adrenal medullary chromaffin cells. We found the inhibition of NGF-induced neuronal differentiation of PC12 cells by HA via inhibition of ERK and p38 MAPK activation, caused by the interaction of hyaluronic acid to its receptor, RHAMM [102]. 
Our results indicated that HA sponge is useful for local regeneration of dental pulp, whereas HA gel inhibits the differentiation or neurite outgrowth of neurons. In vivo, our results showed that HA sponge is gradually biodegraded during the regeneration processes, leaving soluble HA in the regenerated dental pulp. The biological and physiological behaviors of HA throughout regeneration of dental pulp should be clarified.

\section{Conclusion}

Throughout this review, we discussed local regeneration therapy of dental pulp with dentin and periapical tissues. Except for some studies, growth factors and scaffolds are exogenously supplied as biomaterials, while the sources of stem or progenitor cells are dependent on the residual tissues. For these local regeneration therapies of dental pulp and periapical tissues, controls of infection and inflammatory responses are critical points to preserve the vitality of residual tissues. To achieve complete infection control, the development of anti-microbial dental materials with an ability to seal the defect area is important. The resin bonding system with composite resin is commonly used as one of materials showing favorable adhesion to enamel and dentin, and there are some reports about anti-microbial composite resin [103-105], which may inhibit further bacterial invasion after tissue regeneration of dental pulp and periapical tissues. Regarding the control of inflammatory responses, it has been reported that the available clinical data supporting the efficacy of BMP2 in clinical trial are not all robust [82,106,107], and inflammation at the target site may be one of the inhibitors against BMP2 induced tissue regeneration. It is important to develop exogenous supplementation of anti-inflammatory molecules, as well as an accurate method for assessing the vitality of the residual dental pulp.

\section{Acknowledgements}

This review was supported by Grants in Aid for Scientific Research (C.K., T.N., E.J.) from The Ministry of Education, Science, and Culture of Japan, Tokyo, Japan.

\section{References}

1. Kitamura, C.; Kimura, K.; Nakayama, T.; Toyoshima, K.; Terashita, M. Primary and secondary induction of apoptosis in odontoblasts after cavity preparation of rat molars. J. Dent. Res. 2001, 80, 1530-1534.

2. Kitamura, C.; Ogawa, Y.; Nishihara, T.; Morotomi, T.; Terashita, M. Transient co-localization of c-Jun N-terminal kinase and c-Jun with heat shock protein 70 in pulp cells during apoptosis. J. Dent. Res. 2003, 82, 91-95.

3. Kitamura, C.; Nishihara, T.; Ueno, Y.; Nagayoshi, M.; Kasugai, S.; Terashita, M. Thermotolerance of pulp cells and phagocytosis of apoptotic pulp cells by surviving pulp cells following heat stress. J. Cell. Biochem. 2005, 94, 826-834.

4. Kitamura, C.; Nishihara, T.; Ueno, Y.; Chen, K.-K.; Morotomi, T.; Yano, J.; Nagayoshi, M.; Terashita, M. Effects of sequential exposure to lipopolysaccharide and heat stress on dental pulp cells. J. Cell. Biochem. 2006, 99, 797-806. 
5. Ueno, Y.; Kitamura, C.; Terashita, M.; Nishihara, T. Re-oxygenation improves hypoxia-induced pulp cell arrest. J. Dent. Res. 2006, 85, 824-828.

6. Smith, A.J.; Cassidy, N.; Perry, H.; Bègue-Kirn, C.; Ruch, J.V.; Lesot, H. Reactionary dentinogenesis. Int. J. Dev. Biol. 1995, 39, 273-280.

7. Mitsiadis, T.A.; Fried, K.; Goridis, C. Reactivation of Delta-Notch signaling after injury: complementary expression patterns of ligand and receptor in dental pulp. Exp. Cell. Res. 1999, 246, 312-318.

8. Kawagishi, E.; Nakakura-Ohshima, K.; Nomura, S.; Ohshima, H. Pulpal responses to cavity preparation in aged rat molars. Cell Tissue Res. 2006, 326, 111-122.

9. van Nieuwenhuysen, J.P.; Aouar, M.; D'Hoore, W. Retreatment or radiographic monitoring in endodontics. Int. Endod. J. 1994, 27, 75-81.

10. Rotstein, I.; Salehrabi, R.; Forrest, J.L. Endodontic treatment outcome: Survey of oral health care professionals. J. Endod. 2006, 32, 399-403.

11. Imura, N.; Pinheiro, E.T.; Gomes, B.P.; Zaia, A.A.; Ferraz, C.C.; Souza-Filho, F.J. The outcome of endodontic treatment: A retrospective study of 2,000 cases performed by a specialist. J. Endod. 2007, 33, 1278-1282.

12. Ng, Y.L.; Mann, V.; Gulabivala, K. Outcome of secondary root canal treatment: A systematic review of the literature. Int. Endod. J. 2008, 41, 1026-1046.

13. Discher, D.E.; Mooney, D.J.; Zandstra, P.W. Growth factors, matrices, and forces combine and control stem cells. Science 2009, 324, 1673-1677.

14. Yelick, P.C.; Vacanti, J.P. Bioengineered teeth from tooth bud cells. Dent. Clin. N. Am. 2006, 50, 191-203.

15. Duailibi, S.E.; Duailibi, M.T.; Zhang, W.; Asrican, R.; Vacanti, J.P.; Yelick, P.C. Bioengineered dental tissues grown in the rat jaw. J. Dent. Res. 2008, 87, 745-750.

16. Duailibi, M.T.; Duailibi, S.E.; Young, C.S.; Bartlett, J.D.; Vacanti, J.P.; Yelick, P.C. Bioengineered teeth from cultured rat tooth bud cells. J. Dent. Res. 2004, 83, 523-528.

17. Honda, M.J.; Sumita, Y.; Kagami, H.; Ueda, M. Histological and immunohistochemical studies of tissue engineered odontogenesis. Arch. Histol. Cytol. 2005, 68, 89-101.

18. Sumita, Y.; Honda, M.J.; Ohara, T.; Tsuchiya, S.; Sagara, H.; Kagami, H.; Ueda, M. Performance of collagen sponge as a 3-D scaffold for tooth-tissue engineering. Biomaterials 2006, 27, 3238-3248.

19. Honda, M.; Morikawa, N.; Hata, K.; Yada, T.; Morita, S.; Ueda, M.; Kimata, K. Rat costochondral cell characteristics on poly(L-lactide-co-epsilon-caprolactone) scaffolds. Biomaterials 2003, 24, 3511-3519.

20. Zheng, L.; Yang, F.; Shen, H.; Hu, X.; Mochizuki, C.; Sato, M.; Wang, S.; Zhang, Y. The effect of composition of calcium phosphate composite scaffolds on the formation of tooth tissue from human dental pulp stem cells. Biomaterials 2011, 32, 7053-7059.

21. Yuan, Z.; Nie, H.; Wang, S.; Lee, C.H.; Li, A.; Fu, S.Y.; Zhou, H.; Chen, L.; Mao, J. Biomaterial selection for tooth regeneration. Tissue Eng. Part B Rev. 2001, 17, 373-388.

22. Nakao, K.; Morita, R.; Saji, Y.; Ishida, K.; Tomita, Y.; Ogawa, M.; Saitoh, M.; Tomooka, Y.; Tsuji, T. The development of a bioengineered organ germ method. Nat. Methods 2007, 4, 227-230. 
23. Ishida, K.; Murofushi, M.; Nakao, K.; Morita, R.; Ogawa, M.; Tsuji, T. The regulation of tooth morphogenesis is associated with epithelial cell proliferation and the expression of Sonic hedgehog through epithelial-mesenchymal interactions. Biochem. Biophys. Res. Commun. 2011, 405, 455-461.

24. Ikeda, E.; Morita, R.; Nakao, K.; Ishida, K.; Nakamura, T.; Takano-Yamamoto, T.; Ogawa, M.; Mizuno, M.; Kasugai, S.; Tsuji, T. Fully functional bioengineered tooth replacement as an organ replacement therapy. Proc. Natl. Acad. Sci. USA 2009, 106, 13475-13480.

25. Ikeda, E.; Tsuji, T. Growing bioengineered teeth from single cells: Potential for dental regenerative medicine. Expert Opin. Biol. Ther. 2008, 8, 735-744.

26. Rutherford, R.B.; Gu, K. Treatment of inflamed ferret dental pulps with recombinant bone morphogenetic protein-7. Eur. J. Oral Sci. 2000, 108, 202-206.

27. Six, N.; Lasfargues, J.J.; Goldberg, M. Differential repair responses in the coronal and radicular areas of the exposed rat molar pulp induced by recombinant human bone morphogenetic protein 7 (osteogenic protein 1). Arch. Oral Biol. 2002, 47, 177-187.

28. Nakamura, Y.; Slaby, I.; Spahr, A.; Pezeshki, G.; Matsumoto, K.; Lyngstadaas, S.P. Ameloblastin fusion protein enhances pulpal healing and dentin formation in porcine teeth. Calcif. Tissue Int. 2006, 78, 278-284.

29. Nakashima, M. Induction of dentin formation on canine amputated pulp by recombinant human bone morphogenetic proteins (BMP)-2 and -4. J. Dent. Res. 1994, 73, 1515-1522.

30. Nakashima, M.; Tachibana, K.; Iohara, K.; Ito, M.; Ishikawa, M.; Akamine, A. Induction of reparative dentin formation by ultrasound-mediated gene delivery of growth/differentiation factor 11. Hum. Gene Ther. 2003, 14, 591-597.

31. Nakashima, M.; Iohara, K.; Ishikawa, M.; Ito, M.; Tomokiyo, A.; Tanaka, T.; Akamine, A. Stimulation of reparative dentin formation by ex vivo gene therapy using dental pulp stem cells electrotransfected with growth/differentiation factor 11 (Gdf11). Hum. Gene Ther. 2004, 15, 1045-1053.

32. Nakashima, M.; Mizunuma, K.; Murakami, T.; Akamine, A. Induction of dental pulp stem cell differentiation into odontoblasts by electroporation-mediated gene delivery of growth/differentiation factor 11 (Gdf11). Gene Ther. 2002, 9, 814-818.

33. Iohara, K.; Nakashima, M.; Ito, M.; Ishikawa, M.; Nakasima, A.; Akamine, A. Dentin regeneration by dental pulp stem cell therapy with recombinant human bone morphogenetic protein 2. J. Dent. Res. 2004, 83, 590-595.

34. Nakashima, M.; Iohara, K.; Zheng, L. Gene therapy for dentin regeneration with bone morphogenetic proteins. Curr. Gene Ther. 2006, 6, 551-560.

35. Iohara, K.; Zheng, L.; Ito, M.; Ishizaka, R.; Nakamura, H.; Into, T.; Matsushita, K.; Nakashima, M. Regeneration of dental pulp after pulpotomy by transplantation of CD31(-)/CD146(-) side population cells from a canine tooth. Regen. Med. 2009, 4, 377-385.

36. Nakashima, M. Tissue engineering in endodontics. Aust. Endod. J. 2005, 31, 111-113.

37. Tsuboi, T.; Mizutani, S.; Nakano, M.; Hirukawa, K.; Togari, A. Fgf-2 regulates enamel and dentine formation in mouse tooth germ. Calcif. Tissue Int. 2003, 73, 496-501.

38. Madan, A.K.; Kramer, B. Immunolocalization of fibroblast growth factor-2 (FGF-2) in the developing root and supporting structures of the murine tooth. J. Mol. Histol. 2005, 36, 171-178. 
39. Tran-Hung, L.; Mathieu, S.; About, I. Role of human pulp fibroblasts in angiogenesis. J. Dent. Res. 2006, 85, 819-823.

40. Tabata, Y.; Ikada, Y. Vascularization effect of basic fibroblast growth factor released from gelatin hydrogels with different biodegradabilities. Biomaterials 1999, 20, 2169-2175.

41. Tabata, Y.; Miyao, M.; Inamoto, T.; Ishii, T.; Hirano, Y.; Yamaoki, Y.; Ikada, Y. De novo formation of adipose tissue by controlled release of basic fibroblast growth factor. Tissue Eng. 2000, 6, 279-289.

42. Tabata, Y.; Nagano, A.; Ikada, Y. Biodegradation of hydrogel carrier incorporating fibroblast growth factor. Tissue Eng. 1999, 5, 127-138.

43. Yamamoto, M.; Ikada, Y.; Tabata, Y. Controlled release of growth factors based on biodegradation of gelatin hydrogel. J. Biomater. Sci. Polym. Ed. 2001, 12, 77-88.

44. Kikuchi, N.; Kitamura, C.; Morotomi, T.; Inuyama, Y.; Ishimatsu, H.; Tabata, Y.; Nishihara, T.; Terashita, M. Formation of dentin-like particles in dentin defects above exposed pulp by controlled release of fibroblast growth factor 2 from gelatin hydrogels. J. Endod. 2007, 33, 1198-1202.

45. Ishimatsu, H.; Kitamura, C.; Morotomi, T.; Tabata, Y.; Nishihara, T.; Chen, K.-K.; Terashita, M. Formation of dentinal bridge on surface of regenerated dental pulp in dentin defects by controlled release of fibroblast growth factor-2 from gelatin hydrogels. J Endod. 2009, 35, 858-865.

46. Sonoyama, W.; Liu, Y.; Fang, D.; Yamaza, T.; Seo, B.M.; Zhang, C.; Liu, H.; Gronthos, S.; Wang, C.Y.; Shi, S.; Wang, S. Mesenchymal stem cell-mediated functional tooth regeneration in swine. PLoS one 2006, 20, e79.

47. Sonoyama, W.; Liu, Y.; Yamaza, T.; Tuan, R.S.; Wang, S.; Shi, S.; Huang, G.T. Characterization of the apical papilla and its residing stem cells from human immature permanent teeth: A pilot study. J. Endod. 2008, 34, 166-171.

48. Huang, G.T.; Sonoyama, W.; Liu, Y.; Liu, H.; Wang, S.; Shi, S. The hidden treasure in apical papilla: The potential role in pulp/dentin regeneration and bioroot engineering. J. Endod. 2008, 34, 645-651.

49. Ebert, R.; Zeck, S.; Krug, R.; Meissner-Weigl, J.; Schneider, D.; Seefried, L.; Eulert, J.; Jakob, F. Pulse treatment with zoledronic acid causes sustained commitment of bone marrow derived mesenchymal stem cells for osteogenic differentiation. Bone 2009, 44, 858-864.

50. Abdallah, B.M.; Kassem, M. The use of mesenchymal (skeletal) stem cells for treatment of degenerative diseases: Current status and future perspectives. J. Cell Physiol. 2009, 218, 9-12.

51. Lim, T.Y.; Wang, W.; Shi, Z.; Poh, C.K.; Neoh, K.G. Human bone marrow-derived mesenchymal stem cells and osteoblast differentiation on titanium with surface-grafted chitosan and immobilized bone morphogenetic protein-2. J. Mater. Sci. Mater. Med. 2009, 20, 1-10.

52. Wan, X.C.; Liu, C.P.; Li, M.; Hong, D.; Li, D.M.; Chen, H.X.; Li, J.C. Staphylococcal enterotoxin $\mathrm{C}$ injection in combination with ascorbic acid promotes the differentiation of bone marrow-derived mesenchymal stem cells into osteoblasts in vitro. Biochem. Biophys. Res. Commun. 2008, 373, 488-492.

53. Post, S.; Abdallah, B.M.; Bentzon, J.F.; Kassem, M. Demonstration of the presence of independent pre-osteoblastic and pre-adipocytic cell populations in bone marrow-derived mesenchymal stem cells. Bone 2008, 43, 32-39. 
54. Lavery, K.; Swain, P.; Falb, D.; Alaoui-Ismaili, M.H. BMP-2/4 and BMP-6/7 differentially utilize cell surface receptors to induce osteoblastic differentiation of human bone marrow-derived mesenchymal stem cells. J. Biol. Chem. 2008, 283, 20948-20958.

55. Walker, J. Relief from chronic pain by low power laser irradiation. Neurosci. Lett. 1983, 43, 339-344.

56. Rochkind, S.; Nissan, M.; Razon, N.; Schwartz, M.; Bartal, A. Electorophysical effect in He-Ne laser on normal and injured sciatic nerve in the rat. Acta Neurochir. 1986, 83, 125-130.

57. Anders, J.J.; Borke, R.C.; Woolery, S.K.; Van de Merwe, W.P. Low power laser irradiation alters the rate of regeneration of the rat facial nerve. Lasers Surg. Med. 1992, 13, 72-82.

58. Honmura, A.; Yanase, M.; Obata, J.; Haruki, E. Therapeutic effect of Ga-Al-As diode laser irradiation on experimentally induced inflammation in rats. Lasers Surg. Med. 1992, 12 , 441-449.

59. Shimizu, N.; Yamaguchi, M.; Goseki, T.; Shibata, Y.; Takiguchi, H.; Iwasawa, T.; Abiko, Y. Inhibition of prostaglandin E2 and interleukin 1-b production by low-power laser irradiation in stretched human periodontal ligament cells. J. Dent. Res. 1995, 74, 1382-1388.

60. Mester, E.; Mester, A.F.; Mester, A. The biomedical effects of laser application. Laser Surg. Med. 1985, 5, 31-39.

61. Conlan, M.J.; Rapley, J.W.; Cobb, C.M. Biostimulation of wound healing by low-energy laser irradiation. J. Clin. Periodontol. 1996, 23, 492-496.

62. Utsunomiya, T. A histopathological study of the effects of low-power laser irradiation on wound healing of exposed dental pulp tissues in dogs, with special reference to lectins and collagens. J. Endod. 1998, 24, 187-193.

63. Murakami, Y.; Unno, A.; Kimura, Y.; Okano, T.; Hossain, M.; Nakamura, Y.; Matsumoto, K. A histochemical study of the regeneration process after injury by pulsed Nd:YAG laser irradiation of root canals. Acta Histochem. 2002, 104, 131-137.

64. Tate, Y.; Yoshiba, K.; Yoshiba, N.; Iwaku, M.; Okiji, T.; Ohshima, H. Odontoblast responses to GaAlAs laser irradiation in rat molars: An experimental study using heat-shock protein-25 immunohistochemistry. Eur. J. Oral Sci. 2006, 114, 50-57.

65. Suzuki, M.; Ogisu, T.; Kato, C.; Shinkai, K.; Katoh, Y. Effect of $\mathrm{CO}_{2}$ laser irradiation on wound healing of exposed rat pulp. Odontology 2011, 99, 34-44.

66. Bayat, M.; Javadieh, F.; Dadpay, M. Effect of He-Ne laser radiation on healing of osteochondral defect in rabbit: A histological study. J. Rehabil. Res. Dev. 2009, 46, 1135-1142.

67. Sculean, A.; Schwarz, F.; Berakdar, M.; Windisch, P.; Arweiler, N.B.; Romanos, G.E. Healing of intrabony defects following surgical treatment with or without an Er:YAG laser. J. Clin. Periodontol. 2004, 31, 604-608.

68. Khadra, M.; Kasem, N.; Haanaes, H.R.; Ellingsen, J.E.; Lyngstadaas, S.P. Enhancement of bone formation in rat calvarial bone defects using low-level laser therapy. Oral Surg. Oral Med. Oral Pathol. Oral Radiol. Endod. 2004, 97, 693-700.

69. Guzzardella, G.A.; Fini, M.; Torricelli, P.; Giavaresi, G.; Giardino, R. Laser stimulation on bone defect healing: an in vitro study. Lasers Med. Sci. 2002, 17, 216-220.

70. McDavid, V.G.; Cobb, C.M.; Rapley, J.W.; Glaros, A.G.; Spencer, P. Laser irradiation of bone: III. Long-term healing following treatment by $\mathrm{CO}_{2}$ and Nd:YAG lasers. J. Periodontol. 2001, 72, 174-182. 
71. Romanos, G.E.; Nentwig, G.H. Regenerative therapy of deep peri-implant infrabony defects after $\mathrm{CO}_{2}$ laser implant surface decontamination. Int. J. Periodontics Restorative Dent. 2008, 28, 245-255.

72. da Silva, R.V.; Camilli, J.A. Repair of bone defects treated with autogenous bone graft and low-power laser. J. Craniofac. Surg. 2006, 17, 297-301.

73. Pinheiro, A.L.; Limeira Júnior Fde, A.; Gerbi, M.E.; Ramalho, L.M.; Marzola, C.; Ponzi, E.A. Effect of low level laser therapy on the repair of bone defects grafted with inorganic bovine bone. Braz. Dent. J. 2003, 14, 177-181.

74. Barbos Pinheiro, A.L.; Limeira Júnior Fde, A.; Márquez Gerbi, M.E.; Pedreira Ramalho, L.M.; Marzola, C.; Carneiro Ponzi, E.A.; Oliveira Soares, A.; Bandeira De Carvalho, L.C.; Vieira Lima, H.C.; Oliveira Gonçalves, T. Effect of 830-nm laser light on the repair of bone defects grafted with inorganic bovine bone and decalcified cortical osseous membrane. J. Clin. Laser Med. Surg. 2003, 21, 383-388.

75. Ozcelik, O.; Cenk Haytac, M.; Seydaoglu, G. Enamel matrix derivative and low-level laser therapy in the treatment of intra-bony defects: A randomized placebo-controlled clinical trial. J. Clin. Periodontol. 2008, 35, 147-156.

76. Denadai, A.S.; de Carvalho Pde, T.; dos Reis, F.A.; Belchior, A.C.; Pereira, D.M.; Dourado, D.M.; Silva, I.S.; de Oliveira, L.V. Morphometric and histological analysis of low-power laser influence on bone morphogenetic protein in bone defects repair. Lasers Med. Sci. 2009, 24, 689-695.

77. Pinheiro, A.L.; Martinez Gerbi, M.E.; Carneiro Ponzi, E.A.; Pedreira Ramalho, L.M.; Marques, A.M.; Carvalho, C.M.; Santos Rde, C.; Oliveira, P.C.; Nóia, M. Infrared laser light further improves bone healing when associated with bone morphogenetic proteins and guided bone regeneration: an in vivo study in a rodent model. Photomed. Laser Surg. 2008, 26, 167-174.

78. Carvalho Pde, T.; Silva, I.S.; Reis, F.A.; Belchior, A.C.; Facco, G.G.; Guimarães, R.N.; Fernandes, G.H.; Denadai, A.S. Effect of $650 \mathrm{~nm}$ low-power laser on bone morphogenetic protein in bone defects induced in rat femors. Acta Cir. Bras. 2006, 21, 63-68.

79. Hirata, S.; Kitamura, C.; Fukushiama, H.; Nakamichi, I.; Abiko, Y.; Terashita, M.; Jimi, E. Low-level laser irradiation enhances BMP-induced osteoblast differentiation by stimulating the BMP/Smad signaling pathway. J. Cell. Biochem. 2010, 111, 1445-1452.

80. Horst, M.; Madduri, S.; Gobet, R.; Sulser, T.; Hall, H.; Eberli, D. Scaffold characteristics for functional hollow organ regeneration. Materials 2010, 3, 241-263.

81. Sundelacruz, S.; Kaplana, D. Stem cell- and scaffold-based tissue engineering approaches to osteochondral regenerative medicine. Semin. Cell Dev. Biol. 2009, 20, 646-655.

82. McKay, W.F.; Peckham, S.M.; Badura, J.M. A comprehensive clinical review of recombinant human bone morphogenetic protein-2 (INFUSE Bone Graft). Int. Orthop. 2007, 31, 729-734.

83. Geiger, M.; Li, R.H.; Friess, W. Collagen sponges for bone regeneration with rhBMP-2. Adv. Drug Deliv. Rev. 2003, 55, 1613-1629.

84. Uemura, T.; Dong, J.; Wang, Y.; Kojima, H.; Saito, T.; Iejima, D.; Kikuchi, M.; Tanaka, J.; Tateishi, T. Transplantation of cultured bone cells using combinations of scaffolds and culture techniques. Biomaterials 2003, 24, 2277-2286. 
85. Angele, P.; Kujat, R.; Nerlich, M.; Yoo, J.; Goldberg, V.; Johnstone, B. Engineering of osteochondral tissue with bone marrow mesenchymal progenitor cells in a derivatized hyaluronan-gelatin composite sponge. Tissue Eng. 1999, 5, 545-554.

86. Ramamurthi, A.; Vesely, I. Smooth muscle cell adhesion on crosslinked hyaluronan gels. J. Biomed. Mater. Res. 2002, 60, 195-205.

87. Liu, Y.; Shu, X.Z.; Gray, S.D.; Prestwich, G.D. Disulfide-crosslinked hyaluronan-gelatin sponge: Growth of fibrous tissue in vivo. J. Biomed. Mater. Res. A 2004, 68, 142-149.

88. Kim, H.D.; Valentini, R.F. Retention and activity of BMP-2 in hyaluronic acid-based scaffolds in vitro. J. Biomed. Mater. Res. 2002, 59, 573-584.

89. Peattie, R.A.; Nayate, A.P.; Firpo, M.A.; Shelby, F.J.; Fisher, R.J.; Prestwich, G.D. Stimulation of in vivo angiogenesis by cytokine-loaded hyaluronic acid hydrogel implants. Biomaterials 2004, 25, 2789-2798.

90. Fraser, J.R.E.; Laurent, T.C.; Laurent, U.B.G. Hyaluronan: Its nature, distribution, functions and turnover. J. Intern. Med. 1997, 242, 27-33.

91. Dowthwaite, G.P.; Edwards, J.C.W.; Pitsillides, A.A. An essential role for the interaction between hyaluronan and hyaluronan binding proteins during joint development. J. Histochem. Cytochem. 1998, 46, 641-651.

92. Day, A.J.; Sheehan, J. Hyaluronan: Polysaccharide chaos to protein organization. Curr. Opin. Struct. Biol. 2001, 11, 617-622.

93. Liesegang, T.J. Viscoelastic substances in ophthalmology. Surv. Ophthalmol. 1990, 34, 268-293.

94. Fukuda, K.; Dan, H.; Takayama, M.; Kumano, F.; Saitoh, M.; Tanaka, S. Hyaluronic acid increases proteoglycan synthesis in bovine articular cartilage in the presence of interleukin-1. J. Pharmacol. Exp. Ther. 1996, 277, 1672-1675.

95. Linde, A. A study of the dental pulp glycosaminoglycans from permanent human teeth and rat and rabbit incisors. Arch. Oral Biol. 1973, 18, 49-59.

96. Sakamoto, N.; Okamoto, H.; Okuda, K. Qualitative and quantitative analyses of bovine, rabbit, and human dental pulp glycosaminoglycans. J. Dent. Res. 1979, 58, 646-655.

97. Felszeghy, S.; Hyttinen, M.; Tammi, R.; Tammi, M.; Módis, L. Quantitative image analysis of hyaluronan expression in human tooth germs. Eur. J. Oral Sci. 2000, 108, 320-326.

98. Sasaki, T.; Kawamata-Kido, H. Providing an environment for reparative dentine induction in amputated rat molar pulp by high molecular-weight hyaluronic acid. Arch. Oral Biol. 1995, 40, 209-219.

99. Kuo, T.F.; Huang, A.T; Chang, H.H.; Lin, F.H.; Chen, S.T.; Chen, R.S.; Chou, C.H.; Lin, H.C.; Chiang, H.; Chen, M.H. Regeneration of dentin-pulp complex with cementum and periodontal ligament formation using dental bud cells in gelatin-chondroitin-hyaluronan tri-copolymer scaffold in swine. J. Biomed. Mater. Res. A 2008, 86, 1062-1068.

100. Nomiyama, K.; Kitamura, C.; Tsujisawa, T.; Nagayoshi, M.; Morotomi, T.; Terashita, M.; Nishihara, T. Effects of lipopolysaccharide on newly established rat dental pulp derived cell line with odontoblastic properties. J. Endod. 2007, 33, 1187-1191.

101. Inuyama, Y.; Kitamura, C.; Nishihara, T.; Morotomi, T.; Nagayoshi, M.; Tabata, Y.; Matsuo, K.; Chen, K.-K.; Terashita, M. Effects of hyaluronic acid sponge as a scaffold on odontoblastic cell line and amputated dental pulp. J. Biomed. Mater. Res. B Appl. Biomater. 2010, 92, 120-128. 
102. Washio, A.; Kitamura, C.; Jimi, E.; Terashita, M.; Nishihara, T. Mechanisms involved in suppression of NGF-induced neuronal differentiation of PC12 cells by hyaluronic acid. Exp. Cell Res. 2009, 315, 3036-3043.

103. Izutani, N.; Imazato, S.; Nakajo, K.; Takahashi, N.; Takahashi, Y.; Ebisu, S.; Russell, R.R. Effects of the antibacterial monomer 12-methacryloyloxydodecylpyridinium bromide (MDPB) on bacterial viability and metabolism. Eur. J. Oral Sci. 2011, 119, 175-181.

104. Imazato, S. Bio-active restorative materials with antibacterial effects: New dimension of innovation in restorative dentistry. Dent. Mater. J. 2009, 28, 11-19.

105. Imazato, S.; Tay, F.R.; Kaneshiro, A.V.; Takahashi, Y.; Ebisu, S. An in vivo evaluation of bonding ability of comprehensive antibacterial adhesive system incorporating MDPB. Dent. Mater. 2007, 23, 170-176.

106. Kusumoto, K.; Bessho, K.; Fujimura, K.; Akioka, J.; Okubo, Y.; Wang, Y.; Iizuka, T.; Ogawa, Y. Osteoinduction by recombinant human bone morphogenetic protein-2 in muscles of non-human primates. J. Int. Med. Res. 2002, 30, 251-259.

107. Vaidya, R.; Sethi, A.; Bartol, S.; Jacobson, M.; Coe, C.; Craig, J.G. Complications in the use of rhBMP-2 in PEEK cages for interbody spinal fusions. J. Spinal Disord. Tech. 2008, 21, 557-562.

(C) 2011 by the authors; licensee MDPI, Basel, Switzerland. This article is an open access article distributed under the terms and conditions of the Creative Commons Attribution license (http://creativecommons.org/licenses/by/3.0/). 